\title{
Review of Open and Equitable Scholarly Communications: Creating a More Inclusive Future
}

Jennifer Putnam Davis

Augusta University

Abstract: Review of Maron, N., Kennison, R., Bracke, P., Hall, N., Gilman, I., Malenfant, K., Roh, C., \& Shorish, Y. (2019). Open and equitable scholarly communications: Creating a more inclusive future. Chicago: Association of College and Research Libraries.

Keywords: scholarly communications, "gendered language", "non-white" production, open educational resources, open access publication, diversity and inclusion

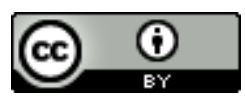

This is an Open Access article distributed under the terms of the Creative Commons Attribution 4.0 International License (http://creativecommons.org/licenses/by/4.0), which permits unrestricted use, distribution, and reproduction in any medium, provided the original work is properly cited. 
In their introduction, the authors redefine the term "scholarly communications" to include the process of research, from creating the research to publicizing it, instead of focusing on just research outputs. This definition provides a more inclusive approach to managing and transforming how research is conducted and how it is shared. Inclusivity itself is a larger theme addressed in this research agenda, and the authors take careful consideration to defining this ambiguous term. Their systematic approach is appreciated; they first performed a literature review to gather definitions of the concepts of inclusivity, open, and equitable, then hosted focus groups and conducted a survey. The reader is encouraged to start with the introduction to understand the context before diving in to each section.

Sections are organized by themes: People, Content, and Systems. People is probably the easiest of the three to address and so is presented first. The authors identify areas of progress based on commitments by library organizations. Particular emphasis is given to implementations of diversity and inclusion plans, active recruitment, and residency programs to foster the advancement of those who are traditionally underrepresented. Most helpful, is the authors' sections on practical actions, which list projects that could be undertaken to promote change. Similarly, the authors also provide sections on future directions for research and identify specific research questions that can address diversity and inclusion. Most advantageous are their sample research projects given.

Content is largely characterized by metrics for promotion, retention, and tenure. The authors advocate for a shift in recognizing open educational resources and open access 
publishing in faculty portfolios. Also minimally addressed is the topic of implicit and explicit bias, which is described as biases towards "gendered" language and "non-white" production. Issues of discoverability of content from the Global South is also presented as a bias. It would be more advantageous if the authors expounded upon this section more rather than the metrics for promotion and tenure, because they present interesting biases that many may not even realize; for example, how search engines pull content from largely the western world.

Systems refers to digital infrastructures and financial systems, both of which cause major barriers in the transmission of research. This section is not as clearly defined as the previous sections, but the authors accurately list creating standards, providing accessibility for people with disabilities, investment in innovation, and tool development for strategic decision-making as areas of progress. Developing funding models for authors to have opportunities to publish and open access is more straightforward. The section on supporting sustainable technological infrastructure is more complex, perhaps due to the very nature of this topic. The authors pose questions that many academic libraries currently struggle with how to subsidize time and effort to create and maintain digital systems that work as they are supposed to. A small section on data management is presented, which could have been expanded more given that data is a growing trend emphasized in research. Another section that the authors could have emphasized more is designing systems that focus on users and audience.

This research agenda demonstrates ACRL's commitment to broadening the library's role in scholarly communications. Instead of merely providing support, this agenda advocates Journal of New Librarianship, 5(2020) pp. 87-89 10.21173/newlibs/9/9 
for a more integral role for the library within the context of institutions, faculty and

researchers, and publishers. This is a positive shift for libraries to demonstrate their value to their communities. 